\title{
ERRATUM
}

\section{Erratum to: Conductive grease synthesized using nanometer ATO as an additive}

\author{
Xiangyu GE, Yanqiu XIA*, Zongying SHU, Xiaopei ZHAO \\ School of Energy Power and Mechanical Engineering, North China Electric Power University, Beijing 102206, China \\ Received: 17 November 2014 / Revised: 11 January 2015 / Accepted: 21 January 2015
}

(C) The author(s) 2015. This article is published with open access at Springerlink.com

\section{Erratum to}

Friction 3(1): 56-64 (2015)

DOI 10.1007/s40544-015-0073-7

1. The original version of this article contained the incorrect expression on page 56, instead of "polyethylene oxide polypropylene oxide tinbutadiene styrene ether 50HB660 (PAG)".

It should read "poly (ethylene glycol-ran-propylene glycol) monobutyl ether 50HB660 (PAG)" as more accurate academic expression.

2. The original version of this article contained the incorrect legend "Au" in Fig. 4(b) on page 60, instead of

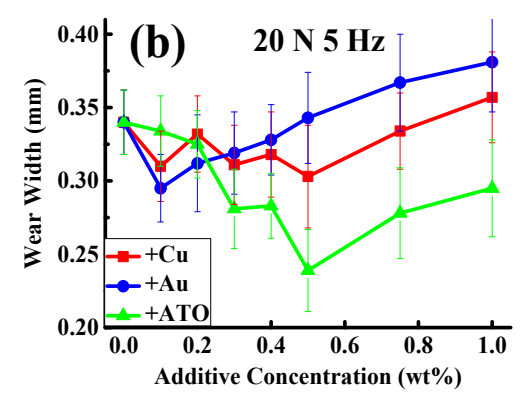

The online version of the original article can be found at http://dx.doi.org/10.1007/s40544-015-0073-7
It should read "Ag" as in the following figure

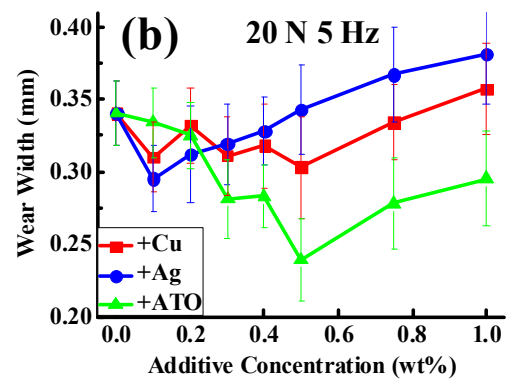

3. The original version of this article contained the incorrect figure in Fig. 7(g) on page 61, instead of

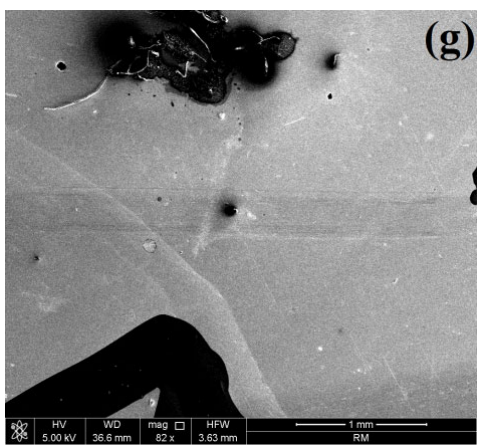

It should read

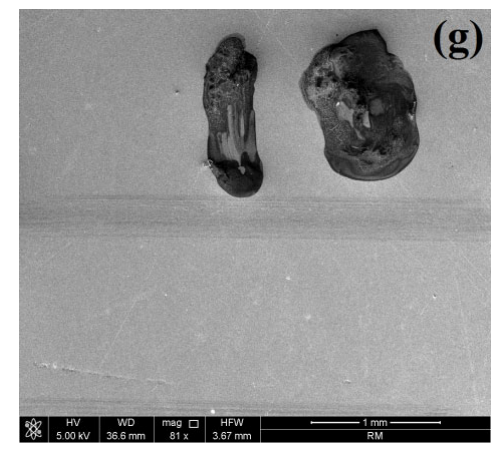

* Corresponding author: Yanqiu XIA.

E-mail: xiayq@ncepu.edu.cn 